\title{
Difficulty-manipulation-based learning effects on throwing performances and achievement goals in young boys
}

\author{
Yousri Elghoul ${ }^{1 凶}$, Fatma Bahri ${ }^{1}$, Mohamed Abdelkader Souissi ${ }^{2,3}$, Nesrine Chaâri ${ }^{4}$, Nizar Souissi ${ }^{2,3}$, and Mohamed Frikha ${ }^{5}$ \\ ${ }^{1}$ High Institute of Sport and Physical Education, Sfax University, Sfax, Tunisia; ${ }^{2}$ High Institute of Sport and Physical Education Ksar- \\ Said, Manouba University, Manouba, Tunisia; ${ }^{3}$ Research Unit Physical Activity, Sport and Health, National Observatory of Sport, \\ Tunis, Tunisia; ${ }^{4}$ Faculty of Sciences, Carthage University, Bizerte, Tunisia; and ${ }^{5}$ Department of Physical Education, College of Educa- \\ tion, King Faisal University, Al-Hufüf, Kingdom of Saudi Arabia
}

\begin{abstract}
Background: Motor development in essential for ensuring mastery in daily motor activities. Nonetheless, skill acquisition is still requiring strategies inducing efficient motor learning. Objective: The aim of this research is to investigate whether a short period of learning a novel psychomotor task, based on difficulty manipulation, affects throwing performances and achievement goals adoption and stability in 11-12-year-old boys. Methods: Forty-one right-handed boys ( $M \pm S D$; age $11.3 \pm 0.4$ years, body height $147 \pm 8.94$ $\mathrm{cm}$, body mass $40.57 \pm 8.1 \mathrm{~kg}$ ) were assigned to either control group (no difficulty manipulations), experimental group 1 (one dimension difficulty manipulation obtained by increasing the distance of the throws), and experimental group 2 (two-dimension difficulty with progressive manipulation of both distance and dartboard dimension). Three sessions were conducted within one week: pre-test, post-test, and retention test. Performance was evaluated by the accuracy (the mean score and the numbers of zeros) and consistency (the coefficients of variation). Two conditions were investigated: free condition and time pressure condition. For comparison of the tests, the analysis of variance was used. Bland and Altman correlations were used to assess the relationships between variables. Results: This study demonstrated that only the experimental group 1 made significant improvement in accuracy performance with better mean scores in the retention test when compared to the post-test $(p=.01)$, and in a consistency measure with lower values at the retention test than at the post-test $(p<.001)$. The control group made a higher number of errors at the retention test after time pressure condition than free condition $(p=.02)$. Mean scores were found to be significantly correlated with consistency and errors ( $r=.81$ and .78 , respectively). However, analyses did not show significant dependence between achievement goals adoption for all groups. Conclusions: Accordingly, the progressive manipulation of difficulty level plays a major role in the improvement and durability of learning in the retention phase. However, it was not related to a change in the achievement goals adoption and stability.
\end{abstract}

Keywords: task difficulty, fine motor skill, goal adoption, young boys

\section{Introduction}

In childhood, motor development is a basic process to ensure mastery in the face of daily motor activities. In order to optimize motor learning, researchers have tried to investigate an abundance of strategies inducing efficiency in skill acquisition. Manipulation of task difficulty (TD) is one, amongst others, of these strategies (Elghoul et al., 2018). Referring to literature, TD is defined as the nature of the work to be accomplished (Locke et al., 1981). Previously, it has been reported that the manipulation of TD is an intervention which used to influence objective performance, success perceptions, perceptions of feedback error, interpretations of success during skill acquisition (Ong et al., 2015) or to find a suitable combination of the throwing distance and the size of a target for adult (Zahradník et al., 2008). The findings supported the fact that changes in target size influence the perception of success and self-efficacy (Ong et al., 2015). Interestingly, this manipulation did not affect the interpretation of error feedback and performance in a delayed retention test. Recent evidence suggesting improved motor learning in the delayed test as a result of the use of TD strategies. More recently, it has been suggested the evidence of an effective accuracy improvement in the delayed test based on the use of TD strategies (Elghoul et al., 2018). Moreover, the previous study validated the hypothesis that the smaller targets are, indeed, a bigger challenge for the participants than the bigger ones (Frömer et al., 2012). On the contrary, in the dart-throwing task, evidence would be provided that the reduced field of view appears more effective to record better performance than the large one. The increased field would contain more visual stimuli distracting or irrelevant environment information to be processed (Koyuncu, 2011). Recently, research question assumptions and results related to success-related manipulations for task performance and mechanisms related to target size manipulations (Ong et al., 2019).

\footnotetext{
$\triangle$ Corresponding author: Yousri Elghoul, e-mail yosri.elghoul@isseps.usf.tn, ORCID ${ }^{\circledR}$ record https://orcid.org/0000-0002-7095-7479

Article history: Received September 8 2020, Accepted February 28 2021, Published March 222021

Copyright: (c) 2021 The Author(s). Published by Palacký University Olomouc. This is an open access article distributed under the terms of the Creative Commons Attribution License (https://creativecommons.org/licenses/by/4.0/), which permits unrestricted use, distribution, and reproduction in any medium, provided the original author and source are credited. This license does not cover any third-party material that may appear with permission in the article.
} 
According to the achievement motivation theory, behavioral differences, thereafter motivation and the amount of effort depend on TD. More perceived difficulty level increases, the greater investment effort in the task is large (Wright \& Kirby, 2001). Moreover, results advanced that increasing levels of difficulty affect the level of the perceived ability of performance-approach goals and positive affect (Kumar \& Jagacinski, 2011). Despite the fact that perceived ability is conceptually distinct from achievement motivation, participants could perceive similarly the TD and react differently by changing the level of effort (Elliot $\&$ Church, 1997). Interestingly, the expected effort is adjusted proportionally to the difficulty of the task. In addition, contrary to easy tasks, for very difficult tasks, effort investment is low irrespective of potential motivation and success is viewed as impossible and not worthwhile (Capa et al., 2008). With reference to literature, achievement goals are typically defined as purpose directed behavior (Elliot \& McGregor, 1999; Maehr, 1983).

The subject orientation in mastery-approach is to improve the individuals' own ability. In such a goal, learning is characterized by cultivating the sensitivity of individual perception and the autonomy of behavior (Dysvik \& Kuvaas, 2010). In mastery-avoidance goal, individuals actively adopt various measures with the aim to avoid any drop in performance (Madjar et al., 2011). The goal of the performance-approach is more oriented towards the best demonstrating ability and the subject expects to get a positive ability evaluation (Roussel et al., 2011). Individuals develop the need not just to develop or demonstrate competence but also to avoid developing or displaying incompetence (Spray \& Warburton, 2011). The effect of TD on the goal-outcome relationship has received less than adequate attention (Zhang et al., 2016). Moreover, little is known about the stability or continuity of goals adoption (Spray \& Warburton, 2011). Based on the transactional nature of the relationships between goals adoption and competence, it remains unclear if any change in competence predicts influence goal's adoption (Spray \& Warburton, 2011). The limited research effort, however, has been exerted to investigate the role of TD in relation to other constructs such as achievement outcomes (Li et al., 2007) and factors predicting learning outcomes like goals and learning interest (Zhang et al., 2016) and more experimental difficult tasks (Capa et al., 2008).

Therefore, the aim of the current study was to investigate the effect of a short learning period of a novel psychomotor task based on task difficulty manipulation on throwing performance and goal adoption and stability in 11-12-year-old boys.

\section{Methods}

\section{Participants}

Forty-one boys $(M \pm S D$; age $11.30 \pm 0.4$ years, body height $147 \pm 8.94 \mathrm{~cm}$, body mass $40.57 \pm 5.1 \mathrm{~kg}$ ) were volunteers to participate in this experiment. All participants were right-handed and had no prior experience with the experimental task.
Once included, written informed consent was obtained from all participants' parents after receiving a thorough explanation of the protocol. Participants were assigned to either a control group (CG, $n=15)$ with standard difficulty level (regular distance and darts size), an experimental group 1 (E1D; one-dimension difficulty, $n=13$ ) with a difficulty level obtained by modifying distance to the target $(2 \mathrm{~m}, 2.37 \mathrm{~m}, 3.56 \mathrm{~m})$ and an experimental group 2 (E2D; two-dimensions difficulty, $n=13$ ) with difficulty level obtained by modified both distance and target size (45 $\mathrm{cm}, 30 \mathrm{~cm}, 15 \mathrm{~cm}$; Table 1). Different groups were fixed with the constraint that participants were approximately matched to pre-test performance (i.e., throwing nine darts to strike as close as possible to the bull's eye), from the regular distance (i.e., $2.37 \mathrm{~m}$; Elghoul et al., 2014; Ong et al., 2015) and following two experimental stress conditions (with and without time-pressure; Frikha et al., 2016). The protocol was conducted in accordance with the Declaration of Helsinki (1975, revised 1983) and the local Ethics Committee approval (EM2S-180026).

\section{Procedures}

Subjects performed a dart-throwing across two experimental sessions. A pre-test followed by an acquisition phase and an immediate post-test during the first session. In the second session, a delayed retention test was performed one week later (Ong et al., 2015). Three warm-up jets introduced each session. Two conditions were investigated during test sessions. In the first, the free condition (FC), participants were instructed to complete a trial of nine darts and to aim for the bull's eye. In the second, time pressure condition (TPC), subjects were instructed to complete all the throws as quickly and accurately as possible (Elghoul et al., 2014; Frikha et al., 2016). The pre-test consists of 9 trials. During the acquisition phase, participants were asked to complete a set of 9 blocks of 9 trials of darts throwing. The acquisition phase was followed by an immediate post-test, which procedure was similar to the pre-test. The delayed retention test, consisting of 9 trials, was administered one week later. After each test session, participants were invited to complete a goal-setting questionnaire (Elliot \& Church, 1997).

The E1D practiced dart throwing by increasing the distance to the dartboard. Three jet conditions were retained: short distance (i.e., $2 \mathrm{~m}$ ), regular distance (i.e., $2.37 \mathrm{~m}$ ), and long distance (i.e., $3.56 \mathrm{~m}$; Edwards \& Waterhouse, 2009; Elghoul et al., 2014, Frikha et al., 2016). The increase of difficulty level for the E2D was obtained by the manipulation of distance to the target (same as for the E1D) and dartboard size. Three sizes were maintained: 45 $\mathrm{cm}$ (regular), $30 \mathrm{~cm}$, and $15 \mathrm{~cm}$ (Table 1). The dartboard size was modified by covering the surface with a circle of black material from the side to inside (Koyuncu, 2011). The CG throws a dart with the same standard task (regular distance and official dartboard diameter). Dartboard height was manipulated so that its center was at eye level for each participant (Elghoul et al., 2014). No instructions were given to the participants. Individuals' posture and throwing techniques were maintained the same in the test conditions. 


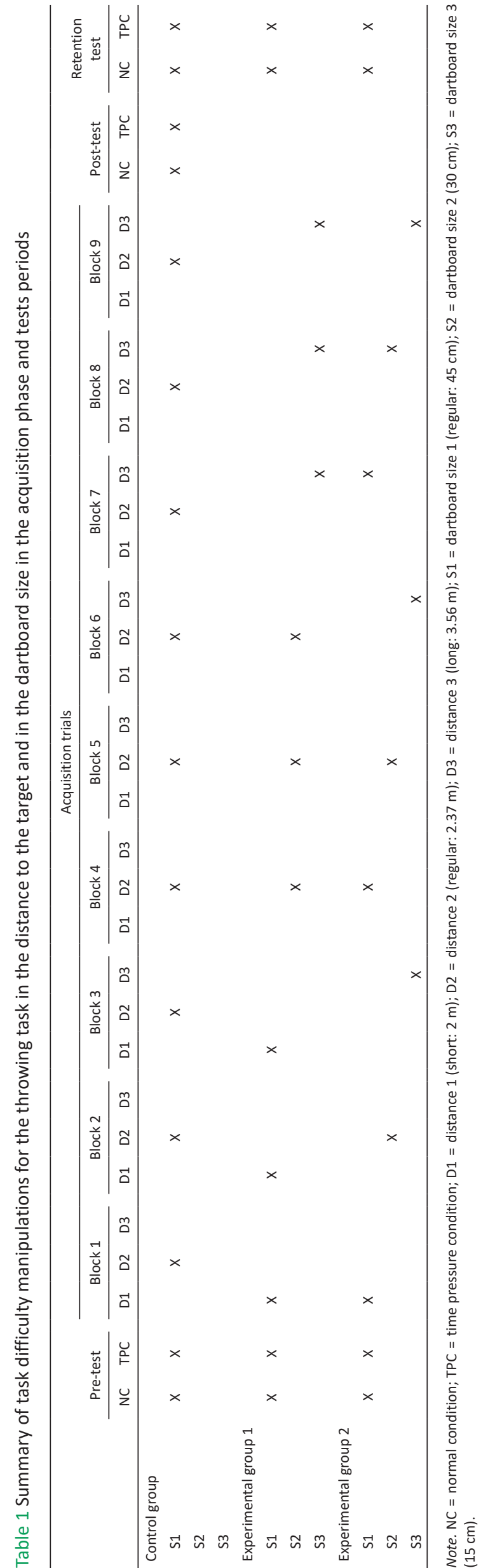

\section{Score calculations}

Each throw was scored according to its position on the board (0-10). A dart that missed the board, or that bounced off was given a score of zero. The target consisted of a series of 10 concentric rings for the standard conditions, and areas will be restrained in accordance with each experimental condition. Accuracy and consistency were evaluated by using three scores (Edwards \& Waterhouse, 2009; Elghoul et al., 2014): the first was the mean score of the bloc throws. This score could range from 0 (all misses) to 10 (all bull's eyes); a high score indicating high accuracy. The second score was the numbers of zeros scored (the number of times the target was missed or bounced off). This score could range from 0 to 9. A low number of zeros indicates high accuracy. The third measure of performance was the coefficient of variation (CV) of the scores: $S D$ score divided by mean score. A lower coefficient indicates a higher consistency.

\section{Measures}

The Achievement Goal of the participants' achievement goals were assessed using the Elliot and Church (1997) scale. This model encompasses three goals constructs: mastery goals, performance-approach goals, and performanceavoidance goals. Participants were instructed to indicate how true each statement was of them on a scale of 1 ("not true of me") to 7 ("extremely true of me"). The reliability analysis showed Cronbach's alpha values: .76, .63 and .76 respectively to mastery goals, performance-approach goals, and performance-avoidance goals.

\section{Data analysis}

All statistical analyses were performed using Statistica (Version 10; StatSoft, Tulsa, OK, USA). Data are presented in the text as means and standard deviations. Distributions normality was checked using the Shapiro-Wilks test. As data were normally distributed, the calculated and measured variables were analyzed using two-way analysis of variance (ANOVA) with repeated measures for the two factors Learning Phase (T1 vs. T2 vs. T3) $\times$ Throwing Condition (FC vs. TPC). These ANOVAs were performed separately for each of the three groups (CG, E1D and E2D). When appropriate, significant differences among means were tested using a Bonferroni post-hoc test. Pearson's chisquared test with Yates correction was applied to compare achievement goals adoption. Bland and Altman (1995) correlations were used to assess the relationships between variables. Effect sizes were calculated as partial eta-squared $\left(\eta_{\mathrm{p}}^{2}\right)$ to estimate the meaningfulness of significant findings, where value of $.20, .50$ and .80 represent small, moderate, and large effect sizes (Cohen, 1988). The level of statistical significance was set at $p<.05$.

\section{Results}

\section{Performance measures}

Accuracy (mean scores) parameter was considered for this action. The repeated measures ANOVA performed separately on the E1D revealed a significant Learning Phase effect $\left(F(2,24)=3.67, p=.04, \eta_{\mathrm{p}}^{2}=.23\right)$, a no significant 
Throwing Condition effect $(F(1,12)=0.40, p=.54$, $\left.\eta_{\mathrm{p}}^{2}=.03\right)$, and a no significant interaction of Learning Phase $\times$ Throwing Condition $(F(2,24)=0.40, p=.68$, $\left.\eta_{\mathrm{p}}^{2}=.03\right)$. The post-hoc analysis showed an improvement in accuracy values only in retention tests. Confirming the success of the strategy of difficulty manipulation, the E1D made better mean scores in T3 when compared to T2 $(p=.01)$ and when compared to T1 ( $p=.04$; Figure 1). Regarding the E2D, ANOVA revealed a no significant Learning Phase effect for the accuracy $(F(2,24)=0.92$, $\left.p=.41, \eta_{\mathrm{p}}^{2}=.07\right)$, a no significant Throwing Condition effect $\left(F(1,12)=0.02, p=.87, \eta_{\mathrm{p}}^{2}=.00\right)$, and a no significant interaction of Learning Phase $\times$ Throwing Condition $\left(F(2,24)=0.26, p=.77, \eta_{p}^{2}=.02\right)$. Concerning the accuracy of the $C G$, the repeated measures ANOVA showed a no significant Learning Phase effect $(F(2,28)=0.33$, $\left.p=.72, \eta_{\mathrm{p}}^{2}=.02\right)$, a no significant Throwing Condition effect $\left(F(1,14)=0.59, p=.46, \eta_{\mathrm{p}}^{2}=.04\right)$, and a no significant interaction of Learning Phase $\times$ Throwing Condition $\left(F(2,28)=0.93, p=.41, \eta_{\mathrm{p}}^{2}=.06\right)$.

The coefficient of variation (CV; consistency measure), parameter was considered for this action. The repeated measures ANOVA performed separately for the E1D shows a significant Learning Phase effect $(F(2,24)=4.32$,

Figure 1 Means scores across groups in dart throwing tasks

\section{$\square C G$ 口E1D $\square E 2 D$}

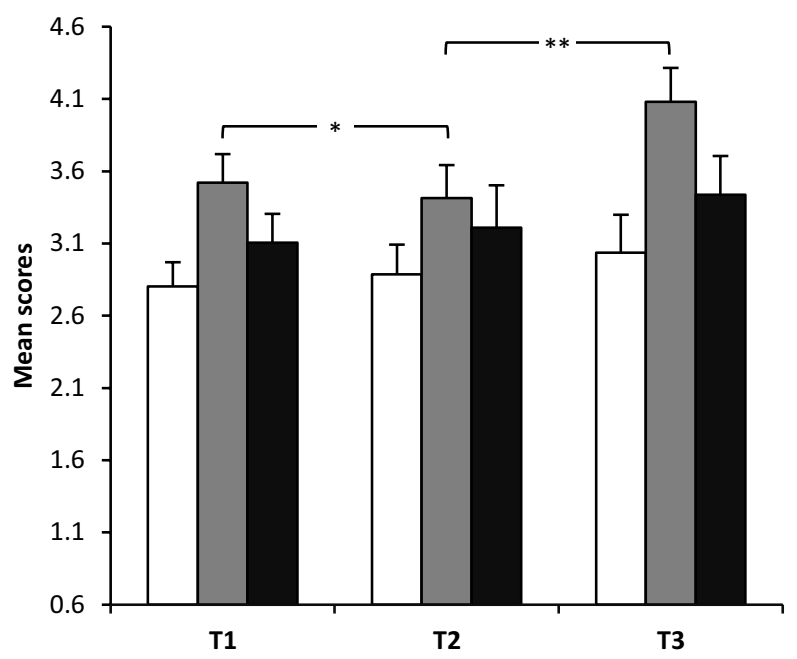

Note. All values are $M \pm S E . C G=$ control group; $E 1 D=$ experimental group 1 $E 2 \mathrm{D}=$ experimental group $2 ; \mathrm{T} 1=$ pre-test, $\mathrm{T} 2=$ post-test, $\mathrm{T} 3=$ retention test. ${ }^{*} p<.05,{ }^{* *} p<.01$ $\left.p=.02, \eta_{\mathrm{p}}^{2}=.26\right)$, a no significant Throwing Condition effect $\left(F(1,12)=0.00, p=.98, \eta_{\mathrm{p}}^{2}=.00\right)$, and a no significant interaction of Learning Phase $\times$ Throwing Condition $\left(F(2,24)=0.43, p=.65, \eta_{\mathrm{p}}^{2}=.03\right)$. With respect to the learning phases, post-hoc testing indicated that $\mathrm{CV}$ was lower during the retention phase compared with the posttest $(p<.001$; Figure 2$)$. In addition, Bland and Altman test showed a significant correlation between the coefficient of variation and means scores $(r=.81$; Table 2$)$. Regarding the E2D, ANOVA revealed a no significant Learning Phase effect for the $\operatorname{CV}\left(F(2,24)=0.24, p=.79, \eta_{\mathrm{p}}^{2}=.02\right)$, a no significant Throwing Condition effect $(F(1,12)=0.26$, $\left.p=.62, \eta_{\mathrm{p}}^{2}=.02\right)$, and a no significant interaction of Learning Phase $\times$ Throwing Condition $(F(2,24)=0.17$, $\left.p=.84, \eta_{\mathrm{p}}^{2}=.01\right)$. Finally, concerning the CV of the CG, repeated measures ANOVA revealed a no significant Learning Phase effect $\left(F(2,28)=0.11, p=.90, \eta_{\mathrm{p}}^{2}=.00\right)$, a no significant Throwing Condition effect $(F(1,14)=1.84$, $\left.p=.20, \eta_{\mathrm{p}}^{2}=.12\right)$, and a no significant interaction of Learning Phase $\times$ Throwing Condition $(F(2,28)=2.46$, $\left.p=.10, \eta_{\mathrm{p}}^{2}=.15\right)$.

The number of errors (number of zeros: accuracy measure), parameter was considered for this action. The repeated measures ANOVA performed separately for the E1D

Figure 2 Coefficient of variation across groups in dart throwing tasks

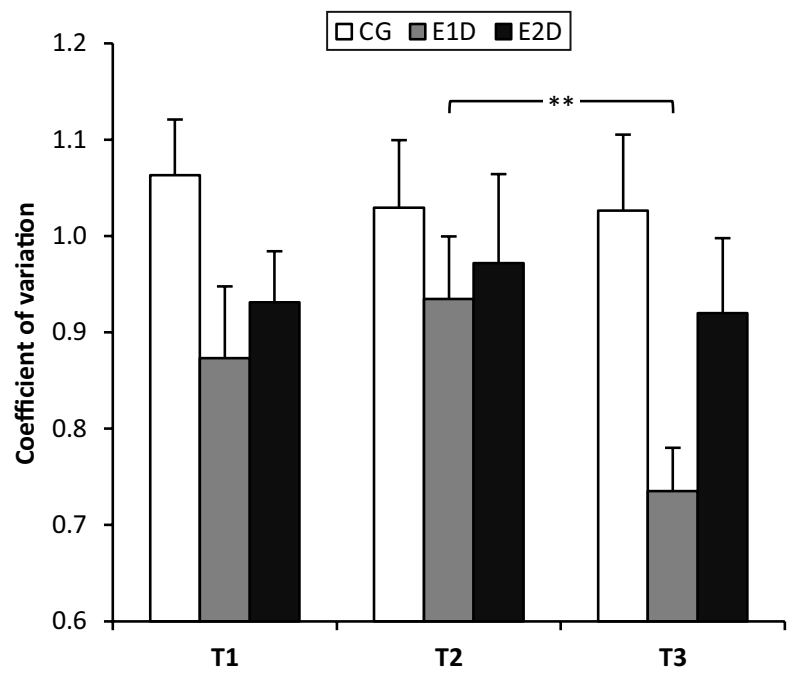

Note. All values are $M \pm S E . C G=$ control group; $E 1 D=$ experimental group 1; $\mathrm{E} 2 \mathrm{D}=$ experimental group $2 ; \mathrm{T} 1=$ pre-test, $\mathrm{T} 2=$ post-test, $\mathrm{T} 3=$ retention test. $*^{*} p<.01$.

Table 2 Correlations between achievement goals and dart throwing scores

\begin{tabular}{lccccc}
\hline & Performance goals & Mastery goals & Avoidance goals & CV & \\
\hline Performance goals & - & & & & \\
Mastery goals & .066 & - & - & & \\
Avoidance goals & .107 & .025 & .134 &. & $.924^{*}$ \\
CV & .088 & -.103 & .121 & $.816^{*}$ &. \\
Errors & .172 & -.087 & .089 & $.781^{*}$ \\
Mean scores & -.040 & -.185 & & \\
\hline
\end{tabular}

Note. $\mathrm{CV}=$ coefficient of variation scores. ${ }^{*} p<.05$. 
shows a significant Learning Phase effect $(F(2,24)=1.78$, $\left.p=.19, \eta_{\mathrm{p}}^{2}=.13\right)$, a no significant Throwing Condition effect $\left(F(1,12)=0.01, p=.94, \eta_{\mathrm{p}}^{2}=.00\right)$, and no significant interaction of Learning Phase $\times$ Throwing Condition $\left(F(2,24)=1.20, p=.32, \eta_{\mathrm{p}}^{2}=.09\right)$. Concerning the errors of the E2D, ANOVA revealed a no significant Learning Phase effect $\left(F(2,24)=0.03, p=.97, \eta_{\mathrm{p}}^{2}=.00\right)$, a no significant Throwing Condition effect $(F(1,12)=0.00$, $\left.p=.99, \eta_{\mathrm{p}}^{2}=.00\right)$, and a no significant interaction of Learning Phase $\times$ Throwing Condition $(F(2,24)=0.11$, $\left.p=.89, \eta_{\mathrm{p}}^{2}=.00\right)$. The repeated measures ANOVA performed separately for the CG shows a significant Learning Phase effect $\left(F(2,28)=0.17, p=.84, \eta_{\mathrm{p}}^{2}=.01\right)$, a no significant Throwing Condition effect $(F(1,14)=1.36$, $\left.p=.26, \eta_{\mathrm{p}}^{2}=.08\right)$, and a significant interaction of Learning Phase $\times$ Throwing Condition $(F(2,28)=3.58, p=.04$, $\left.\eta_{\mathrm{p}}^{2}=.20\right)$. Regarding interaction, greater accuracy (errors) effects were registered for the less difficult throws condition (FC) during the retention phase compared with the posttest $(p<.001)$. The CG scored a higher number of errors under TPC when compared to FC during the retention test $(p=.02$; Figure 3$)$.

\section{Achievement goals}

Pearson's chi-squared analyses did not show significant dependence between the adoption of achievement goals and the different experimental groups with a level of difficulty manipulations during the learning phases; CG: $\chi^{2}(4)=0.55, p=.97 ; \mathrm{E} 1 \mathrm{D}: \chi^{2}(4)=2.32, p=.68$; and E2D: $\chi^{2}(4)=1.08, p=.89$ (Table 3).

Chi-square of adjustment confirms that the difference between the experimental group's goal adoption in three test periods (pre-test, post-test, and retention) was significant for CG $\left(\chi^{2}(2)=7.78, p=.02\right), \mathrm{E} 1 \mathrm{D}\left(\chi^{2}(2)=38.83\right.$, $p=<.001)$ and E2D $\left(\chi^{2}(2)=21.9, p=<.001\right.$; Table 3$)$.
Mastery-goal approaches were the most adopted goal by the different experimental groups (67.5\%; Table 3). It appears that the progressive difficulty manipulation strategy (large vs. small target) makes the approach of a goal adoption more stable over time. For the E1D, masterygoal adoption was more stable $(82.1 \%)$ with the comparison of self-approach goal adoption $(7.7 \%)$ and avoidance goal $(10.3 \%)$ in the different testing periods. For the E2D, difficulty strategy manipulation appears more advantageous for self-goal approach adoption $(23.1 \%)$ than the other goals in the retention phase (mastery-goal 69.3\%, avoidance-goal 7.7\%; Table 3). Moreover, Bland and Altman test showed no correlation between achieving goals and performance in the dart-throwing (Table 2).

Figure 3 Errors across learning phases for the control group

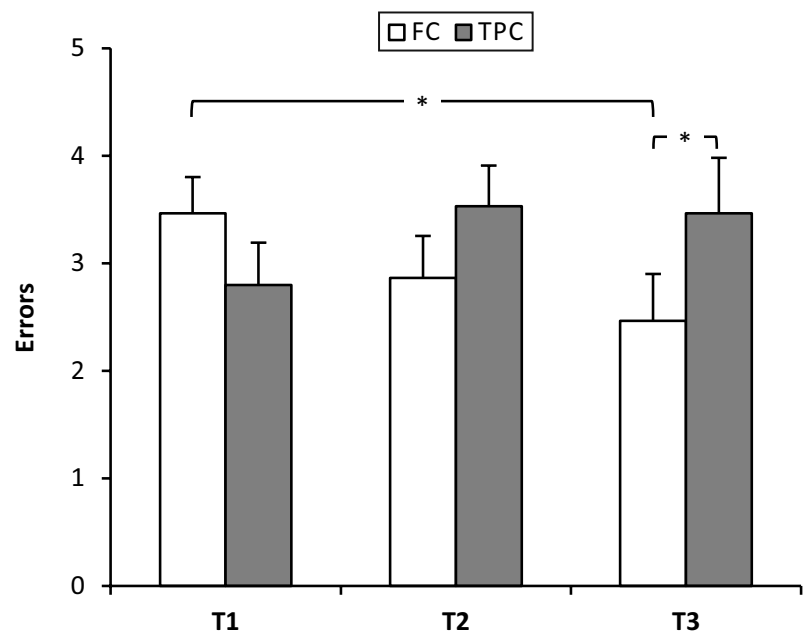

Note. All values are $M \pm S E$. FC $=$ free condition; $T P C=$ time pressure condition; $\mathrm{T} 1=$ pre-test, $\mathrm{T} 2=$ post-test, $\mathrm{T} 3=$ retention test. $* p<.05$

Table 3 Chi-square test results for achievement goals adoption

\begin{tabular}{|c|c|c|c|c|c|c|}
\hline & Avoidance goals & Mastery goals & Performance goals & Total & $\chi^{2}$ & $p$ \\
\hline \multicolumn{7}{|c|}{ Control group } \\
\hline T1 & $4(26.67 \%)$ & $8(53.33 \%)$ & $3(20 \%)$ & 15 & & \\
\hline $\mathrm{T} 2$ & $2(13.33 \%)$ & $8(53.33 \%)$ & $5(33.33 \%)$ & 15 & 0.55 & .969 \\
\hline T3 & $2(13.33 \%)$ & $8(53.33 \%)$ & $5(33.33 \%)$ & 15 & & \\
\hline Total & $8(17.78 \%)$ & $24(53.33 \%)$ & $13(28.89 \%)$ & 45 & 7.78 & .020 \\
\hline \multicolumn{7}{|c|}{ Experimental group 1} \\
\hline $\mathrm{T} 1$ & $3(23.08 \%)$ & $10(76.92 \%)$ & $0(0 \%)$ & 13 & & \\
\hline $\mathrm{T} 2$ & $0(0 \%)$ & $11(84.62 \%)$ & $2(15.38 \%)$ & 13 & 2.32 & .677 \\
\hline T3 & $1(7.69 \%)$ & $11(84.62 \%)$ & $1(7.69 \%)$ & 13 & & \\
\hline Total & $4(10.26 \%)$ & $32(82.05 \%)$ & $3(7.69 \%)$ & 39 & 38.83 & $<.001$ \\
\hline \multicolumn{7}{|c|}{ Experimental group 2} \\
\hline $\mathrm{T} 1$ & $1(7.69 \%)$ & $9(69.23 \%)$ & $3(23.08 \%)$ & 13 & & \\
\hline $\mathrm{T} 2$ & $1(7.69 \%)$ & $10(76.92 \%)$ & $2(15.38 \%)$ & 13 & 1.08 & .897 \\
\hline T3 & $1(7.69 \%)$ & $8(61.54 \%)$ & $4(30.77 \%)$ & 13 & & \\
\hline Total & $3(7.69 \%)$ & $27(69.23 \%)$ & $9(23.08 \%)$ & 39 & 21.90 & $<.001$ \\
\hline \multicolumn{7}{|c|}{ All experimental groups } \\
\hline $\mathrm{T} 1$ & $8(19.51 \%)$ & $27(65.85 \%)$ & $6(14.63 \%)$ & 41 & & \\
\hline $\mathrm{T} 2$ & $3(7.32 \%)$ & $29(70.73 \%)$ & $9(21.95 \%)$ & 41 & 2.35 & .672 \\
\hline T3 & $4(9.76 \%)$ & $27(65.85 \%)$ & $10(24.39 \%)$ & 41 & & \\
\hline Total & $15(12.2 \%)$ & $83(67.48 \%)$ & $25(20.33 \%)$ & 123 & 63.73 & $<.001$ \\
\hline
\end{tabular}

Note. $\mathrm{T} 1=$ pre-test; $\mathrm{T} 2$ = post-test; $\mathrm{T} 3=$ retention test. 


\section{Discussion}

The aim of this study was designed to investigate the effect of a short learning period of novel psychomotor task based on TD manipulation on the throwing performance, the adoption and stability of achievement goals in 11-12-yearold boys. The results demonstrated that progressive manipulation of difficulty level (manipulation of the distance to the target) improves performance of a novel psychomotor task. In fact, the E1D performed a greater accuracy and consistency during the delayed retention test compared to the other experimental groups. Previous research suggests that adding difficulties to the instructional process can increase learning (De Corte, 2003; Roediger \& Karpicke, 2006). Interestingly manipulation of target size did not impact learning as confirmed by the results of the E2D. It appears that manipulations of large to small targets do not always translate to enhance learning (Ong et al., 2015). In addition, this study shows that the progressive difficulty strategy did not affect errors. In previous research, Sawers and Hahn (2013) showed fewer errors and TD perception during practices with gradual training in learning a novel locomotors task. Our result aligns with the recent findings of De Stefani et al. (2020), who found that complex tasks did not show improvements in performance when learning new sports actions. They suggested further investigation on the effects of teaching strategies, specifically, in a complex sequence of motor acts when is performed for the first time.

In addition, an important finding indicates that only the control group recorded a higher number of errors during the delayed retention test in the difficult conditions of throw (TPC) when compared to the less difficult condition (FC; $p=.02$; Figure 3 ). Although the other two groups did not differ in errors across post-test and delayed retention tests after FC and TPC. Elghoul et al. (2018) concluded that integrated progressive difficulty manipulation of the learning process could improve the ability to manage the difficulty level reducing errors under difficult conditions. Earlier studies have demonstrated that adding difficulties during acquisition could encourage the use of implicit learning, enhancing performance in the dart-throwing delayed task (Elghoul et al., 2018) and might produce a higher subsequent level of golf putting performance in the retention phase (Maxwell et al., 2001).

The present research provides initial insight into young people's goal adoption evolution in a relatively short learning period of a novel psychomotor task. In the current investigation, performance in darts throwing did not differ among achievement goals. The results showed that none of the achievement goals did significantly influence performance in learning a novel psychomotor task. This is in accordance with the study of Ntoumanis et al. (2009) which showed that dart-throwing performance did not differ among the achievement goals. In addition, a previous study advanced contrasted results with significantly worse performance in a basketball-dribbling task among students allocated to the performance-avoidance condition when compared to a performance-approach or a mastery condition (Elliot, 2006). The similarity of non-significant findings have been observed when personal achievement goals were held to predict performance. In this experience, it seems that subjects had done practices after a baseline test on their own initiative. This could be explained by the fact that the goal-specific adoptions will result in more stress appraisals (Ntoumanis et al., 2009). As well, other explanations provided by Elliot (2006) do not appear to be fully addressed. On one hand, the improvement in performance could purely explain the performance. On the other hand, the relative novelty of the task and the limited amount of time may limit significant improvements in performance. The authors support the theoretical proposition that perceived competence influences the adoption of goals (Elliot, 1997; Elliot \& Church, 1997; Elliot \& Harackiewicz, 1996). The improvement in dart-throwing performance registered in the retention phase for the group with progressive difficulty manipulation (E1D) is not associated with a change in goal adoption. This finding is supported by Chisquare results and the absence of a significant correlation between, on the one hand, the goal of achievement, and on the other hand the measure of precision and consistency in dart-throwing performance.

However, the present investigation shows a significant difference between the experimental group's goal adoption in three test periods (pre-test, post-test and retention). In fact, mastery-goal approaches were the most adopted goal of the different groups. According to Lazarus (1991), when one is engaged in pursuing important goals, success and experience will be associated with positive emotions, however, failure one's result in negative emotions. Thus, we think that positive progression in performance observed among the different experimental groups, mainly the E1D, was associated with the stability of the adopted mastery goals. In fact, for the E1D, mastery goal adoption was more stable in comparison with self-approach goal adoption and avoidance goal in the different testing periods. Even more, Ntoumanis et al. (2009) viewed that such goal committed was related to personal factors such as volition, choice, selfdetermination and other social-contextual features.

The present results indicate that the manipulation of two dimensions of progressive difficulty is more advantages for self-goal approach adoption than the other goals in the retention phase. The progressive difficulty level of both dartboard dimension and distance appeared therefore as a more competitive strategy.

In this study, we confirmed a slight change in goal adoption associated with the manipulation of two dimensions difficulty level; however, this variation is not generalized into the manipulation of one dimension difficulty as it has little influence on goals pursued. Thus, as mentioned above a short learning period may be insufficient to make distinctive goal-level changes among the different experimental groups.

\section{Study limitations}

To the authors' knowledge, this is the first study examining the effects of a combined short learning period and progressive difficulty manipulation on the acquisition and delayed retention learning of a novel fine motor coordination task, associated with the adoption and stability of achievement goals. 
The most evident limitation of the current study is the small sample size, a limitation that remains under debate regarding the generalization of the results in related effective learning tasks. This issue should be addressed in future studies. This study was also limited by the sample of this study, in which the main aim was to provide preliminary results, and should consider future investigations to explore some other critical aspects (e.g., gender comparison, selfefficacy). Moreover, experimental conditions applied in this study could introduce more learning practices and take into account cognitive processing which might provide new findings and reliable predictors of performance, over time, when learning a novel psychomotor task.

\section{Conclusions}

In summary, this study bridges the concept of the use of level difficulty when learning a novel psychomotor task. Based on progressive manipulation of difficulty manipulation strategies, using a throwing task, this study demonstrates the importance of learning processes regarding the use of the difficulty manipulation theories. Specifically, progressive manipulation of difficulty level, as reflected in the protocol, played a major role in the durability of learning drive in the retention phase. Given the stability in goals adoption, this study demonstrates that achievement goal is often poor predictors of performance for learning a novel psychomotor task. The present study spurs future research to better understand how to associate TD manipulations and learning practices.

\section{Acknowledgments}

We would like to express our gratitude to all people participating in this study.

\section{Conflict of interest}

The authors report no conflict of interest.

\section{References}

Bland, J. M., \& Altman, D. G. (1995). Comparing methods of measurement: Why plotting difference against standard method is misleading. Lancet, 346(8982), 1085-1087. https://doi.org/10.1016/s0140-6736(95)91748-9

Capa, R. L., Audiffren, M., \& Ragot, S. (2008). The effects of achievement motivation, task difficulty, and goal difficulty on physiological, behavioral, and subjective effort. Psychophysiology, 45(5), 859-868. https://doi. org/10.1111/j.1469-8986.2008.00675.x

Cohen, J. (1988). Statistical power analysis for the behavioral sciences (2nd ed.). Lawrence Erlbaum Associates. https://doi.org/10.4324/9780203771587

De Corte, E. (2003). Transfer as the productive use of acquired knowledge, skills, and motivations. Current Directions in Psychological Science, 12(4), 142-146. https://doi.org/10.1111/1467-8721.01250

De Stefani, E., Rodà, F., Volta, E., Pincolini, V., Farnese, A., Rossetti, S., Pedretti, F., \& Ferrari, P. F. (2020). Learning new sport actions: Pilot study to investigate the imitative and the verbal instructive teaching methods in motor education. PloS ONE, 15(8), Article e0237697. https://doi.org/10.1371/journal. pone. 0237697

Dysvik, A., \& Kuvaas, B. (2010). Exploring the relative and combined influence of mastery-approach goals and work intrinsic motivation on employee turnover intention. Personnel Review, 39(5), 622-638. https://doi. org/10.1108/00483481011064172

Edwards, B. J., \& Waterhouse, J. (2009). Effects of one night of partial sleep deprivation upon diurnal rhythms of accuracy and consistency in throwing darts. Chronobiology International, 26(4), 756-768. https://doi. org/10.1080/07420520902929037
Elghoul, Y., Bahri, F., Chaari, N., Ezeddinie, S., Masmoudi, L., Souissi, N., \& Frikha, M. (2018). Effect of difficulty manipulation strategies on acquisition, retention and associated perceptions in fine motor coordination task learning in young school boys. Physical Activity Review, 6, 100-109. https://doi. org/10.16926/par.2018.06.14

Elghoul, Y., Frikha, M., Masmoudi, L., Chtourou, H., Chaouachi, A., Chamari, K., \& Souissi, N. (2014). Diurnal variation of cognitive performance and perceived difficulty in dart-throwing performance in 9-10-year-old boys. Biological Rhythm Research, 45(5), 789-801. https://doi.org/10.1080/09291016.20 14.921409

Elliot, A. J. (1997). Integrating the "classic" and "contemporary" approaches to achievement motivation: A hierarchical model of approach and avoidance achievement motivation. In M. L. Maehr \& P. R. Pintrich (Eds.), Advances in motivation and achievement (Vol. 10, pp. 143-179). JAI Press.

Elliot, A. J. (2006). The hierarchical model of approach-avoidance motivation. Motivation and Emotion, 30, 111-116. https://doi.org/10.1007/s11031-006-9028-7

Elliot, A. J., \& Church, M. A. (1997). A hierarchical model of approach and avoidance motivation. Journal of Personality and Social Psychology, 72(1), 218-232. https://doi.org/10.1037/0022-3514.72.1.218

Elliot, A. J., \& Harackiewicz, J. M. (1996). Approach and avoidance achievement goals and intrinsic motivation: A mediational analysis. Journal of Personality and Social Psychology, 70(3), 461-475. https://doi. org/10.1037/0022-3514.70.3.461

Elliot, A. J., \& McGregor, H. A. (1999). Test anxiety and the hierarchical model of approach and avoidance achievement motivation. Journal of Personality and Social Psychology, 76(4), 628-644. https://doi.org/10.1037/0022-3514.76.4.628

Frikha, M., Chaâri, N., Derbel, M. S., Elghoul, Y., Zinkovsky, A. V., \& Chamari, K. (2016). Acute effect of stretching modalities and time-pressure on accuracy and consistency of throwing darts among 12- and 13-year-old schoolboys. Journal of Sports Medicine and Physical Fitness, 57(9), 1089-1097. https://doi. org/10.23736/S0022-4707.16.06521-X

Frömer, R., Hafner, V., \& Sommer, W. (2012). Aiming for the bull's eye: Preparing for throwing investigated with event-related brain potentials. Psychophysiology, 49(3), 335-344. https://doi.org/10.1111/j.1469-8986.2011.01317.x

Koyuncu, M. (2011). Broadbent's cognitive approach and its effect on motor performance in sports. Psychology, 2(5), 472-476. https://doi.org/10.4236/ psych.2011.25073

Kumar, S., \& Jagacinski, C. M. (2011). Confronting task difficulty in ego involvement: Change in performance goals. Journal of Educational Psychology, 103(3), 664-682. https://doi.org/10.1037/a0023336

Lazarus, R. S. (1991). Emotion and adaptation. Oxford University Press.

Li, W., Lee, A., \& Solmon, M. (2007). The role of perceptions of task difficulty in relation to self-perceptions of ability, intrinsic value, attainment value, and performance. European Physical Education Review, 13(3), 301-318. https:// doi.org/10.1177/1356336X07081797

Locke, E. A., Shaw, K. N., Saari, L. M., \& Latham, G. P. (1981). Goal setting and task performance: 1969-1980. Psychological Bulletin, 90(1), 125-152. https:// doi.org/10.1037/0033-2909.90.1.125

Madjar, N., Kaplan, A., \& Weinstock, M. (2011). Clarifying mastery-avoidance goals in high school: Distinguishing between intrapersonal and task-based standards of competence. Contemporary Educational Psychology, 36(4), 268-279. https://doi.org/10.1016/i.cedpsych.2011.03.003

Maehr, M. L. (1983). On doing well in science: Why Johnny no longer excels, why Sarah never did. In S. Paris, G. Olson, \& H. Stevenson (Eds.), Learning and motivation in the classroom (pp. 179-210). Lawrence Erlbaum Associates. https://doi.org/10.4324/9781315188522

Maxwell, J. P., Masters, R. S. W., Kerr, E., \& Weedon, E. (2001). The implicit benefit of learning without errors. Quarterly Journal of Experimental Psychology Section A, 54(4), 1049-1068. https://doi.org/10.1080/713756014

Ntoumanis, N., Edmunds, J., \& Duda, J. L. (2009). Understanding the coping process from a self-determination theory perspective. British Journal of Health Psychology, 14(2), 249-260. https://doi.org/10.1348/135910708X349352

Ong, N. T., Hawke, J., \& Hodges, N. J. (2019). Target size manipulations affect error-processing duration and success perceptions but not behavioural indices of learning. Brain Sciences, 9(5), Article 119. https://doi.org/10.3390/ brainsci9050119

Ong, N. T., Lohse, K.R., \& Hodges, N. J. (2015). Manipulating target size influences perceptions of success when learning a dart-throwing skill but does not impact retention. Frontiers in Psychology, 6, Article 1378. https://doi. org/10.3389/fpsyg.2015.01378

Roediger, H. L., III, \& Karpicke, J. D. (2006). The power of testing memory: Basic research and implications for educational practice. Perspectives on Psychological Science, 1(3), 181-210. https://doi.org/10.1111/j.1745-6916.2006.00012.x

Roussel, P., Elliot, A. J., \& Feltman, R. (2011). The influence of achievement goals and social goals on help-seeking from peers in an academic context. Learning and Instruction, 21(3), 394-402. https://doi.org/10.1016/j.learninstruc.2010.05.003 Sawers, A., \& Hahn, M. E. (2013). Gradual training reduces practice difficulty while preserving motor learning of a novel locomotor task. Human Movement Science, 32(4), 605-617. https://doi.org/10.1016/i.humov.2013.02.004

Spray, C. M., \& Warburton, V. E. (2011). Temporal relations among multidimensional perceptions of competence and trichotomous achievement goals in physical education. Psychology of Sport and Exercise, 12(5), 515-524. https:// doi.org/10.1016/i.psychsport.2011.04.007 
Wright, R. A., \& Kirby, L. D. (2001). Effort determination of cardiovascular response: An integrative analysis with applications in social psychology. In M. P. Zanna (Ed.), Advances in experimental social psychology (Vol. 33, pp. 255-307). Academic Press.

Zahradník, D., Vaverka, F., \& Gajda, V. (2008). Optimisation of the size of a target and the throwing distance during a throw at a target for adults. Acto
Universitatis Palackianae Olomucensis. Gymnica, 38(4), 39-45. https://gymnica.upol.cz/artkey/gym-200804-0005 Optimisation of the size_of a target and the throwing distance during a throw at a target for adults.php

Zhang, P., Wang, Z., \& Adesope, O. (2016). The effects of goal type, learning interest, and task difficulty on learning English words. International Journal of Learning, Teaching and Educational Research, 15(2), 32-46. https://www. ijlter.org/index.php/iilter/article/view/587 